\title{
Shaping ICT Infrastructure Through Creativity and Innovation
}

\author{
Stephen O. Maitanmi*, Samson O. Ogunlere, and Adesina K. Adio
}

Software Engineering, Dept., Babcock University, Ilisan Remo, Ogun State, Nigeria; maitanmis@babcock.edu.ng

\begin{abstract}
Objectives: Creativity and innovation are the bedrock of any academic exercise. Open distance learning (ODL) should not be an exception. The sustainability of an ODL programme depends on the ability of the teacher to introduce creativity and innovation in the distribution of experiences and resources. Methods/findings: There should be a positive relationship between students and teachers which serves as motivational factors and attractive models for the students. This study develops two infrastructural competency needs that every teacher should possess to drive ODL forward. Application: The study discusses the use and implementation of Zoom and Moodle as ubiquitous interactive learning tools to bridge the gaps between teachers and students.
\end{abstract}

Keywords: ICT, Infrastructure, Creativity, Innovation, ODL, Zoom

\section{Introduction}

Information, communication and technology (ICT) kept advancing at a geometric progression over the years. Educational technologies should keep up with the pace of these developments. Likewise, innovation in information dissemination should follow such development. $-\underline{-3}$ What is then creativity and innovation? Creative learning refers to the possibility for learners to develop their creative skills and learn in a new and creative way. Innovative teachings should involve both the process of teaching for creativity and the application of innovation to teaching practices. Other literatures defined creativity as a product or process that shows a balance of originality and value. It is a skill, an ability to make invisible connections and to generate new and appropriate ideas. From the forgoing, creative learning is therefore any skill which involves understanding and awareness, which enables the learner to go beyond domain acquisition, and focuses on thinking skills. It is based on learners' domain and centeredness. Innovative teaching is the process leading to creative learning. Therefore, open distance learning (ODL) has more emphasis on the process rather than the product, and focuses on the development of thinking and cognitive skills. ${ }^{4,5}$ Similarly, we leave in a knowledgebased economy where most active people want to move on the fast lanes so as to meet up with their responsibilities. Students need to think deeply about cases/scenarios, solve problems creatively, work in teams, communicate clearly in many media, learn technologies as they evolve, and manage information flood. The world is moving at the speed of light; it also requires those who will drive it to understand the intricacies involved in the movement. Therefore, educational technologies such as Zoom and Moodle can facilitate leaners' perception and promote learning competencies in the challenging world.

In line with meeting the world's challenges educationally, one report $\underline{6}$ cited the work carried out in the faculty of education in Thailand four decades ago where most students were required to register for courses that emphasise on the ability to design, develop, implement, and evaluate educational innovations. These courses will empower learners to process knowledge using learnercentred strategies instead of memorising points taught by teachers or facts grabbed from textbooks. If these were done properly, graduates will have the privilege and skills to interpret, analyse and twist resources or information; develop outstanding critical thinking skills, ideas,

${ }^{*}$ Author for correspondence 
opinions; and draw reasonable conclusion which could be communicated to the public for expected feedback.

Creativity and innovation skills are basic skills for learners in the 21 st century. $\underline{\underline{T}}$ This is very possible and true; however, it could be subjective. It is popularly known that the attention spans of youth are reducing every now and then. For this reason, teachers/instructors have moved from a multimedia display of contents to a multimodal display of contents just to capture those who are more interested with audios, videos, and pictures. The integration of YouTube and others necessary teaching aids is the order of event. It has been discussed extensively in literatures that visual learners learn more quickly than non-visual learners. This was supported by ref. - that imagination is more important than knowledge. This means having the strong ability to think might likely bring out the application. Innovations begin with the creative ideas, while some believe that creativity is a starting point for innovations. This study will argue in support of creativity and innovation as not just an opportunity in ODL, but a requirement.

\section{Open Distance Learning}

Distance learning education is not a new concept. It started decades ago as correspondence courses through slow mail (letters) and radio stations. Gradually, it migrated to television stations. From these media to satellite campuses, all was eradicated by the Nigerian Universities Commission (NUC) because of corruption and double standard practices involved. $\stackrel{?}{ }$ Today, education has been taken to where potential students are, which is called ubiquitous learning. Knowledge can be acquired through mobile devices such as tablets, iPad, laptops and other electronic devices provided there is solid and strong internet infrastructure. The use of these electronic devices in education is usually called e-learning. Yusuf supported the idea of distance education; however, he brought in a more advanced skill called open distance education, which was defined as a form of education that operates open door policies, that is, there is no limit to admission. Basically, it means no specific admission periods, nor would there be closing dates for admission; this would be treated extensively in the next paragraph. This type of education is based on industrialised and technological communication. It is noble to know that correspondence courses actually share the same goals and educational philosophy as the face-to-face (traditional) method of delivery. This is now packaged as ODL.
ODL is a technology that allows students to register for programmes at any time in a year, no matter the locations. Such studies would allow students to exchange information at will without barrier to location; this is referred to as ubiquitous studies. Knowledge exchange can take place at anytime, anywhere, and any season. There is no limit to time and place. The consideration of curricular and assessment as key areas to be considered in order to allow free flow of creativity and innovation in the classroom is very paramount; however, the study may not be able to do justice to these areas, but would be more interested in the technological factors that can drive creativity and innovation. Despite this limitation, it is good to know these concepts in brief. The curriculum should be thoroughly developed considering all the required subjects and taking creativity into consideration. Freedom and time for discovery should be allowed while taking learners' interest into account. Assessment should allow creativity to flourish with a great value, at micro, macro, everyday level, and exam level.

As mentioned, open distance education is believed to be the most industrialised form of studies; this system of education is depersonalised both for staff and students as a form of indirect instruction. This is due to its innovative method of delivery which brings about equality in educational opportunities (education for all) which the traditional methods of studies have deprived majority of potential students.

Some of the importance of ODL is mentioned. It was known as a process that breaks down all the traditional barriers to teaching, such asage, location, space, scheduling, style and cost. This is a tremendous achievement to Nigeria specifically; most potential and admissible students are available annually but the approved colleges and universities cannot support them. For example, in 2019, the University Tertiary Matriculation Examination (UMTE) Registrar pointed out that only $25 \%$ got above a score of 200, which means that out of 1,603,181 students who sat for UMTE, 444,696 got above a score of 200 . Based on the Nigerian University Commission's (NUC) approval on the Nigerian universities, there is no vacancy for all the 44,696 students who are eligible in the 171 universities in Nigeria. So, what will happen to others? It is assumed that they will continue to struggle in trying again and again for those who may be able to afford the UMTE fees.

Creativity and innovation in open and distance education is a paradigm for human development in the 21st century 
for nation building in Nigeria. Students should be trained to think critically in finding solutions to problems, which is referred to student-centred and not teacher-centred. We should all be interested in students' voices/opinions, not voices from memorised textbooks or teachers' points of view as mentioned earlier, and that the relationship between education and human resources cannot be overemphasised. Education makes individuals more economically productive, hence educated persons have the potential to contribute maximally to the development of local and national economy. These opinions of Ground are reasonable and logical to every developing economy; no wonder, Marshall in 1981 subscribed to the views by saying that knowledge is the most powerful engine for production because it enables citizens to subdue nature and satisfy their wants. Education has been known to be instrumental in reducing poverty by mitigating its effects on population, heath, and nutrition, and by increasing the value of efficiency of labor offered by the poor.

\section{Importance of Creativity and Innovation to ODL}

Many creative models have been designed and cited in literatures to support and enhance open distance learning/ education. Such examples include $\underline{10}$ who developed a web-based instructional model based on brain-based learning process in a design course for undergraduate students. The instructional process used consist of seven stages: preparation, setting, learning and transformation, designing the concept and application, development, presentation, and evaluation, and celebration of learning. It was observed that the proper implementation of this model will enhance students' creativity.

In ref. 11 collaborative learning and synthetic instructions to foster pre-service teacher's creative learning was used. The model used consisted of six stages: learning management system (LMS) on virtual classroom, collaboration and communication tools, learning contents, media and resources, roles of learners and instructors, learning activities and assessment. LMS has been widely used as a learning management tool to enhance collaborative teaching, and this has really been of great benefit to students and teachers. Grading has been made easier through this method, and students can easily be reached despite various locations. In a similar note, $\underline{12}$ a different model for undergraduate students was implemented. The creative learning model consists of the following: preparation, study content based on course objectives, blended learning approach following the creative problem-solving principles using lateral learning approach, and evaluation. LMS may be incorporated into blended learning approach which combines the traditional classroom training and distance learning. Students can be reached irrespective of locations provided the internet and other infrastructures are available such as laptop and reliable electricity to support both teachers and students, which could be synchronous and asynchronous modes of communication. Another model was also proposed by $\underline{13}-\underline{15}$ which consists of four phases: increased knowledge, design stage to actual implementation, join the network, and share the experience to foster creativity. It was observed from a summarised literature that creativity-fostering teachers are those who 16 :

Encourage students to learn independently;

Have a corporative, socially integrative style of teaching;

Do not neglect mastery of factual knowledge;

Tolerate "sensible" or bold errors;

Promote self-evaluation;

Take questions seriously;

Offer opportunities to work with varied materials under different conditions;

Help students to learn to cope with frustration and failure;

Reward courage as much as being right.

\section{Technologies for Enhancing Creativity and Innovation}

This study is in support that creativity and innovation in ODL is a requirement and not just an opportunity. Three stages were highlighted as methods by which students could be attracted to creativity and innovation. Ref. $\frac{17}{}$ stated that teachers have to attract students' interest and attention in a new way. Secondly, the current dispensation is a jet age, where every learner would prefer to block their ears with audio music, video games and other digital devices. This overwhelming spread of technologies has introduced a new understanding of communication, information retrieval, and processing. Thirdly, creativity is a form of knowledge creation. For all these aforementioned reasons, it appears clear that creativity and innovation are unavoidable conditions for the present and future of ODL. 


\section{Moodle, an Open Source Learning Management System}

Moodle is an acronym for Modular Object Oriented Development Learning Environment. It is a course management system (CMS) which is an open source. Open source means it is free and available through the internet. There are three main objectives of Moodle: cost, infrastructure, and integration. $\frac{18,19}{19}$ It is easy and cheap to secure a server and the integration is quite simple; anyone with little or no programming skill can use it. Educators use Moodle as an example of free LMS to create online course contents. There are no maintenance costs for upgrading except if the administrators would have to buy few plug-ins that may be essential and unavailable for free. LMS is widely used by universities, communities, schools, instructors, courses, and teachers and businesses worldwide. $\underline{20,21}$

\section{Features of Moodle as LMS}

There are three main profiles associated with Moodle, which is a great advantage over other LMS: the administrator, teachers who may also have other designation such as trainers, facilitators, and promoter and the students (learners or participants).

\section{Major Activities in Moodle}

1. Chart: Students are allowed to chart with fellow students and with their lecturers. The chart could be synchronous or asynchronous.

2. Assignment: The teachers enable the assignment section to allow students to turn in an assignment based on agreed time. Teachers also have the privilege of grading the assignment with or without comments.

3. Questions: The administrators or teachers have the privilege to set multiple choice questions with the expected answers.

4. Database: Enable participants to create, maintain, and search a repository of records.

5. Questionnaire: This is used for creating and conducting surveys which has a provision for feedback.

6. Lesson: A lesson allows a lecturer to create conditional pathways through materials.

7. Forum: The forum is for asynchronous discussions between students or lecturers.
8. Glossary: This enables participants to create and maintain a list of definitions.

9. Quiz: Allows the teacher to design and set quizzes which may be automatically marked and feedbacks are shown privately.

10. Workshop: This enables peer assessment.

11. Upload: This enable students and lecturers to upload files.

\section{Zoom, a Video Conferencing Technology}

Zoom is one of the most commonly used synchronous learning tools in online instruction. Video conferencing allows students and teachers to interact in real time, similar to traditional classroom interaction. The privilege of having a visual contact with the instructor gives the students the opportunity to read facial expressions and body language. ${ }^{22}$ Literatures show that students who participated in video conferencing are more motivated to use technology within their courses. Similarly, asynchronous elements in the classroom lead to higher levels of student engagement. $\underline{23}$ This is logical in the sense that such students will be motivated to use computer devices in other areas as mentioned. Video conferencing broadcasts lectures or messages to the location expected, provided the infrastructure is not faulty.

\section{Suggestions for Using Zoom in a Synchronous Course}

The following are suggestions for using Zoom in a synchronous course. It is not mandatory to follow these in detail; the processes will still work provided the right procedure is followed:

1. It requires registration: it is better that users connect with the course to register with their real names for proper identification during the lecture. Also, except otherwise, it is ideal for students and lecturers to include their videos.

2. Microphone awareness: It is better to turn off or mute listener's microphone during a session to reduce background noise. If the teacher requests for contributions, the students could then unmute their microphone to speak. It is always better and ideal that one microphone is unmute at a time. 
3. Set a standard of etiquette: As much as possible, avoid the following activities: side conversations during the use of Zoom, shuffling of papers, tapping pens, and other noise of any kind. The microphone will pick all these distractions easily and most students will lose concentration.

4. Avoid chewing gum, eating and drinking in Zoom session.

5. Always make eye contact with individual that you are speaking to at the remote site by looking into the camera.

6. Show that you are concentrating to the discussion by nodding your head. You can raise your hands in case you have questions or use the chart button for either private or public notifications. Your question should be directed to a particular person.

7. When teaching on camera, always arrive at the virtual space or local room a few minutes to test all devices.

8. Mute your microphone when you are not speaking.

9. Maintain eye contact with students at both locations

10. Speak as if you are in a traditional face-to-face classroom setting.

11. You can reduce environmental noise by closing windows and doors, mute cell phones, turn off computer alert sounds among others.

12. When sharing images, files or video, remember to allow a few minutes for transmission delay.

\section{Advantages and Disadvantages of Using Zoom}

There are a number of advantages attached to online video conferencing:

- Bower (2011) mentioned better collaboration between students and teachers which add to awareness and technological knowledge.

- Positive perceptions of online learning. $\underline{24}$

- Teachers have the opportunity to boost student's achievement through the use of online video; however, users are advised to be cautious and have better understanding of the technology and platform before attempting to use it.

Meanwhile, there are a number of disadvantages associated with the use of online video conferencing. Proper training on the technology is critical to success, and without it, technical issues can impair the quality of the experience. Glitches in software, bandwidth, and connectivity can turn a flawless lesson into a challenging one. Therefore, planning online lectures that use video and other resources requires a vibrant infrastructure and technical support to provide guidance and troubleshooting when necessary. $\underline{25} \underline{\underline{26}}$

\section{Recommendations and Future Research Areas}

The topic has been discussed extensively. However, it appears that other developers and technology users could go a step further by creating sample models of what both LMS and Zoom looks like so that potential learners can understand better. On the same note, this could also be extended to other viewers in order to get their opinions on the subject areas by making it an empirical research where questionnaire and other instruments could be drawn and hypothesis tested and so on.

\section{Conclusion}

Open distance learning/education has been explained in detail along with its benefits to users with respect to creativity and innovation. It has been established that there is no way education would be completed without giving the students a free access to critical thinking, which is one of the basic requirements of our national development. It is therefore advocated for all teachers and scholars not to major on the teacher centred answers but, on the voices, and thoughts from students' dimension.

\section{References}

1. Whattananarong K. Innovation and technical education technology. Bangkok, Thailand: King Mongkut's University of Technology North Bangkok; 2011.

2. Innovation and creativity in education and training in the EU member states: fostering creative learning and supporting innovative teaching literature review on innovation and creativity in $\mathrm{E} \& \mathrm{~T}$ in the $\mathrm{EU}$ member states (ICEAC). [cited 2019 Jan]. https://www.researchgate. net/publication/265996963_Innovation_and_Creativity_ in_Education_and_Training_in_the_EU_Member_ States_Fostering_Creative_Learning_and_Supporting_ Innovative_Teaching_Literature_review_on_Innovation_ and_Creativity_in_ET_in_the_E. 
3. The world is flat: a brief history of the twenty-first century. [cited 2005 Apr 05]. https://www.amazon.in/ World-Flat-History-Twenty-first-Century/dp/0374292884.

4. Online course design for creativity and innovation skills in virtual cultural ASEAN community from research to empirical practice. [cited 2017]. https://online-journals. org/index.php/i-jet/article/view/6032.

5. Learning styles in the ESL/EFL classroom. [cited $2003 \mathrm{Mar}$. https://www.researchgate.net/publication/319416348_ Learning_Styles_in_the_ESLEFL_Classroom_Myths_ and_realities.

6. Seechaliao T. Instructional strategies to support creativity and innovation in education. J Educ Learn. 2017;6(4):201-8.

7. Ogeh OWM, Chiemeka N. Creativity and innovation in open and distance education: a paradigm for human development in the 21st century for nation-building in Nigeria. J Educ Pract. 2015;6(4):143-7.

8. Imagination is more important than knowledge. [cited 1929]. https://quoteinvestigator.com/2013/01/01/einsteinimagination/.

9. Problems and prospects of open and distance education in Nigeria. [cited 2006 Jan]. https://www.researchgate. net/publication/26415979_Problems_and_Prospects_of_ Open_and_Distance_Education_in_Nigeria.

10. Prompan, I. A development of a WEB-based instructional model based on Brain-based learning process in design course to enhance creative thinking of undergraduate students. Bangkok, Thailand: Chulalongkorn University; 2007.

11. Chua TS. Development of a virtual classroom model using collaborative learning and synectics instruction to develop pre-service teachers' creative thinking. Bangkok, Thailand: Chulalongkorn University; 2010.

12. Aulpaijidkul N. Effects of web-based collaborative learning with a discussion board using six thinking hats technique in fundamental arts subject on creative thinking of undergraduate students with different creative thinking levels. Bangkok, Thailand: Chulalongkorn University; 2011.

13. Kanchanachaya N. Development of a blended learning model based on creative problem solving principles using lateral thinking to enhance creative problem solving abilities for instructional media production of pre-service teachers. Bangkok, Thailand: Chulalongkorn University; 2012.

14. Creativity and Innovation in teaching and learning: a Focus on innovative intelligence (I2Q) pilot program. [cited 2018 Jan].https://www.researchgate.net/publication/322700360_ CREATIVITY_AND_INNOVATION_IN_TEACHING_ AND_LEARNING_A_FOCUS_ON_INNOVATIVE_ INTELLIGENCE_I2Q_PILOT_PROGRAM.

15. Review of learning 2.0 practices: JRC-IPTS. [cited $2009 \mathrm{Feb}$ ]. https://www.researchgate.net/publication/256461822_ Review_of_Learning_20_Practices.

16. Bower M. Synchronous collaboration competencies in webconferencing environments - their impact on the learning process. Distance Educ. 2011;32(1):63-83.

17. Simplicio JSC. Teaching classroom educators how to be more effective and creative teachers. Education. 2000;120(4):675-80.

18. New companion to adult educators. [cited 2007]. https:// www.abebooks.com/servlet/BookDetailsPL?ltrec=t\&isbn= 9788187501015\&bi=932131673.

19. African educational journal. [cited 2012]. http://www. netjournals.org/aer_index.html.

20. Creativity in schools: tensions and dilemmas. [cited 2005 Jan]. https://www.researchgate.net/publication/47365026_ Creativity_in_Schools_Tensions_and_Dilemmas.

21. Teaching with Moodle in higher education. [cited 2011]. https://recipp.ipp.pt/bitstream/10400.22/622/1/ TEACHING\%20 W IT H \% 20 MOODLE \% 20 I N \% 20 HIGHER\%20EDUCATION\%20_Final.pdf.

22. Rudd IIDP, Rudd DP. The value of video in online instruction. J Instr Pedagog. 2014;13:1-7.

23. Acosta-Tello E. Enhancing the online class: effective use of synchronous interactive online instruction. Journal of Instructional Pedagog. 2015:17:1-6.

24. Ellingson DA, Notbohm M. Synchronous distance education: using Web conferencing in an MBA accounting course. Am J Bus Educ. 2012;5(5):555-62.

25. Lonie AL, Andrews T. Creating a rich learning environment for remote post-graduate leaners. Educ Rural Aust. 2009;19(1):3-13.

26. Hartsell T, Yuen S. Video streaming in online learning. AACE J. 2006;14(1):31-43. 